\title{
Detection of Virulence Genes for the Entamoeba histolytic Parasite in People with Colorectal Cancer
}

\author{
Ali Slwmee Serhan Al-halaly ${ }^{1}$, Habeeb Waseel Kadhumand ${ }^{2}$, \\ Ahmed Sabah $\mathrm{Ali}^{3}$, Bashar Abd Alkadhim Naji ${ }^{4}$ \\ ${ }^{1}$ Research, ${ }^{2}$ Assit. Prof., ${ }^{3}$ Research, ${ }^{4}$ Research, \\ University of Al-Qadisiyah/College of Science/Department of Biology, Iraq
}

\begin{abstract}
The aims of this study are to determine the virulence factors of parasitic infestation, especially of the $E$. histolytic parasite, for persons with cancer and parasites. This study contain 2 groups: Group (G1) People with cancer and diarrhea due to the parasite (50)and (G2) People with diarrhea and parasites (24), Stool samples were collected from both groups for the purpose of confirming the diagnosis of the microscopically diagnosed parasite,Molecular testing is used to confirm the diagnosis of the parasite first and then determine or diagnose its virulence factors, The result of the diagnosis of the parasite is $(89.189 \%)$ in the study groups as a result of the PCR examination and the result of the diagnosis of the parasite's virulence factor is $100.0 \%$.
\end{abstract}

The study concluded that all parasitic infestations had virulence factors cysteine protease (CP).

Keywords: Virulence factor, Entamoeba histolytica, PCR, colorectal cancer.

\section{Introduction}

Parasites are among the serious health problems that threaten the public health of the human being due to their consumption of large quantities of the host's food in addition to being a major cause of other health problems, the most important of which is diarrhea, which is a cause of death, especially in children under five years of age, as well as anemia, as hemoglobin levels may decrease, especially when Children infected with worms and other intestinal parasites ${ }^{(1)}$. There are some other pathological effects caused by infection with intestinal parasites such as weight loss, loss of appetite, flatulence with pain, nausea, vomiting and fever, as well as causing unacceptable gaps that lead to Limiting or preventing absorption of proteins, carbohydrates and vitamins $^{(2)}$. The most common intestinal parasite is $\mathrm{E}$. histolytica, which causes amebiasis, which causes about fifty million infections, with a mortality rate of more than 100,000 cases annually ${ }^{(3)}$. Numerous studies indicate that infection with intestinal parasites, including the E. histolytic parasite, has a direct effect on the immune response, which prompts the recruitment of white blood cells from the bloodstream to the sites of infection, where the mucous layer of the intestine acts as a barrier to protect against infection with intestinal diseases, where the immunoglobulin IgA is the main component Which is stimulated by the mucous layer of the intestine against intestinal injury, as it works to prevent pathogens from attaching to and remove the mucous barrier ${ }^{(4)}$. Also, having amebic dysentery causes a change in the protein (TFF3), which is a replacement protein secreted at the site of infection, which promotes reorganization. The cytoskeleton and prevents programmed cell death ${ }^{(5)}$, and also there are many studies confirming an elevated level of mucin 2 in the serum of people with amebic dysentery, as well as other vital signs that the parasite plays an important role in changing it is the level of lipids, which increases the level of triglycerides. The E. histolytic destroying tissues and enabling the amoeba to survive and form colonies in the intestine, and among these factors is the production of the tissue-hemolytic amoeba, the cysteine protease $(\mathrm{CP})$ has a role in analyzing the host cells ${ }^{(6)}$. the cysteine stimulates the mucous layer of the colon to secrete mucus from the capsular cells, and the mucus is very attracted to the protein to bind to the Gal/lectin protein present on the surface of the TM, which in turn allows the parasite to form colonies in the intestine and works to inhibit the mucosal barrier ${ }^{(7)}$.

Another virulence factor is the production of the protein Lectin Galactose N-acetyl-D-galactosamine, 
which helps the parasite to attach to the mucous layer of the colon and form colonies. Formation of amebopores to kill host cells The ability of the amoeba to produce a protein capable of forming holes in the lipid membranes of the lumen of the intestine, This protein is found in three types A, B, and C, all of which are present in the histolytic amoeba ${ }^{(8)}$. This protein is composed of 77 amino acids that work to destroy and devour bacteria. According to the amoeba ${ }^{(9)}$.

\section{Materials and Method}

\section{Experimental design:}

\section{This study contain from 2 groups:}

- Diarrhea and Parasite group (G1).

- Diarrhea Parasite and cancer group (G2).

Samples collection (Stool): Stool samples were collected from patients with diarrhea and parasite infections, as well as cancer.

Molecular Examinations for the E. histolytic parasite and virulence factors:

Stool DNA extraction:-For parasite and virulence factor: DNA was extracted from human stool samples using the (Stool DNA extraction presto) kit provided by (Geneaid) Taiwan, according to the company's instructions .

DNA profile: For parasite and virulence factor: The DNA extracted from stool samples was detected by using a Nano dropspectrophotometer, which is used to detect the concentration of DNA, by determining the concentration of the DNA (ng $\backslash \mu 1$ DNA), it is detected.

Diagnostic method using PCR examination: This method included diagnosing the parasite with (PCR) as well as diagnosing the pathogen genes (PCR) for the diagnosed parasites. The PCR technique was performed by using the primers of 18SrRNA genes responsible for diagnosing (E. histolytica) parasite species from DNA extract by filtering (PCR) also from human stool samples according to the method ${ }^{(10)}$. The PCR technique was performed using the primers of the virulence factor genes of Entamoeba histolytica, namely (Entamoebahistolytica cysteine protease (ECP) gene), which is responsible for diagnosing the virulence factor of the parasite.

Gel electrophoresis (PCR) results of diagnosed parasites and their virulence factors: Electrophoresis was performed using a $1.5 \%$ agarose gel to read the result of the polymerase chain reaction, PCR product analysis, according to the instructions of the manufacturer of the kit.

Statistical Analysis: All results in this study were subjected to statistical analysis to find out the significant differences of the studied variables using the tests ${ }^{(11)}$ (One way anova and Fischer exact test) at a probability level $(\mathrm{p}<0.001)^{(12)}($ Schiefer, 1980).

Kits: Provided by (Geneaid) Taiwan

\section{Results}

The results of Molecular tests for the diagnosis of parasites: The polymerase chain reaction (PCR) examination was used to identify the presence of the small ribosomal RNA gene associated with the parasites recorded in the current study and to show the results by gel electrolysis as in Figure (1-1), where Table (1-1) shows the number of patients. Those who suffer from infection with parasites were by $(89.189 \%)$ in the study groups as a result of the PCR examination, where the PCR method was successful in identifying cases infected with parasites within the group of people with cancer and diarrhea with a rate of $(84.0 \%)$. The results of the statistical analysis showed a significant difference below the level of probability $P=(0.048)$.

Table 1-1: Results of PCR examination of stool samples by group

\begin{tabular}{|l|c|c|c|c|c|c|c|c|c|}
\hline P & \multicolumn{3}{|c|}{ Total } & \multicolumn{3}{c|}{ Diarrhea parasite } & \multicolumn{3}{c|}{ Cancer diarrhea } \\
\hline \multirow{2}{*}{$\begin{array}{l}<0.048 \mathrm{~F} \\
\mathrm{~S}\end{array}$} & Percentage & $\begin{array}{c}\text { Total } \\
\text { Infection }\end{array}$ & $\begin{array}{c}\text { The } \\
\text { Examined }\end{array}$ & Percentage & $\begin{array}{c}\text { The } \\
\text { Infection }\end{array}$ & $\begin{array}{c}\text { The } \\
\text { Examined }\end{array}$ & Percentage & $\begin{array}{c}\text { The } \\
\text { Infection }\end{array}$ & $\begin{array}{c}\text { The } \\
\text { Examined }\end{array}$ \\
\cline { 2 - 10 } & 89.18 & 66 & 74 & 100.0 & 24 & 24 & 84.0 & 42 & 50 \\
\hline
\end{tabular}

F: Fischer exact S: significant 


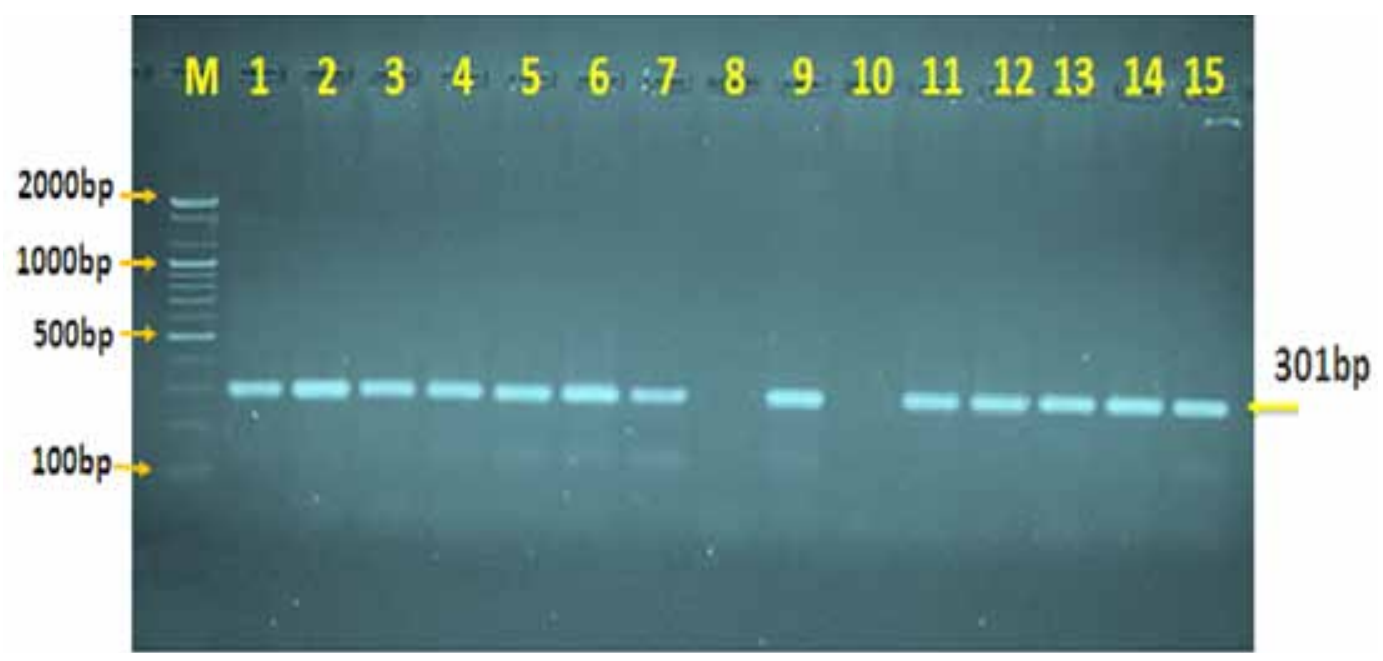

Figure (1-1): The electrophoresis image of agarose gel that showed the analysis of the results of the polymerase chain reaction (PCR) of the small ribosomal RNA gene in the histolytic amoeba from human faecal samples. Where, (M) (2000-100bp): - Sequential scale markers of DNA in the agarose gel Line (1-15) showed the PCR product of the small ribosomal RNA gene in the histolytic amoeba and the positive and negative bundles of the PCR product in (PCR 301bp).
The results of Molecular tests for the diagnosis of virulence factors: The molecular characterization of the cystine protease of E. histolytica was done using the PCR method, and all investigated and diagnosed cases with PCR and gel electrophoresis showed positive results as shown in Table (1-2) and Fig. (1-2).

\section{Descriptive table (1-2) showing the results of virulence genes by PCR examination}

\begin{tabular}{|l|c|c|c|c|c|c|}
\hline Percentage & $\begin{array}{c}\text { Total the } \\
\text { Injured }\end{array}$ & $\begin{array}{c}\text { Total the } \\
\text { Examined }\end{array}$ & Percentage & The Injured & $\begin{array}{c}\text { The } \\
\text { Examined }\end{array}$ & $\begin{array}{c}\text { Gene of parasitecystine } \\
\text { protease }\end{array}$ \\
\hline $100.0 \%$ & 58 & 58 & $100.0 \%$ & 58 & 58 & E. histolytica \\
\hline
\end{tabular}

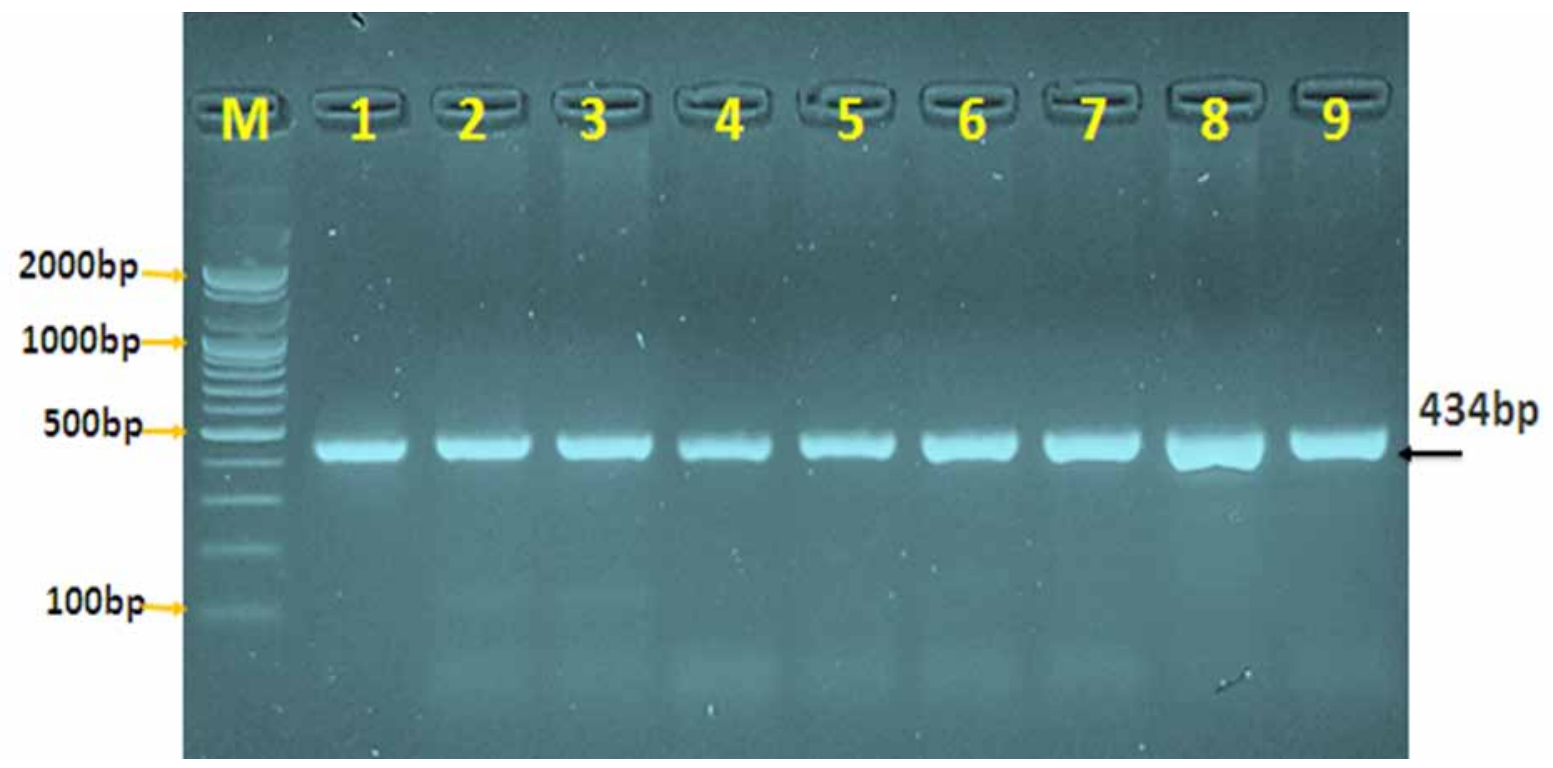


Figure 1-2: Agarose gel electrophoresis image showing results of a polymerase chain reaction (PCR) analysis of the cysteine protease a gene for histolytic amoeba from human fecal samples. Where, (M) (2000100bp): DNA sequence markers. Line (1-9) showed the PCR product of the cysteine protease gene for the E.histolytic and showed the positive bundles of the PCR product in PCR 434bp.

\section{Discussion}

Despite recent advances in diagnostic technology, microscopic examination of stool samples remains pivotal for diagnosing most intestinal pathogenic organisms, including Amoebiasis, which is caused by Entamoeba histolytica parasite, and this test is used in most laboratories $^{(13)}$. The microscopic method is less sensitive compared to other method such as the PCR method, which is considered the ideal method for diagnosis due to the sensitivity and specificity that this examination or diagnostic test possesses ${ }^{(14)}$. Table 1.1 demonstrates the use of PCR assay. As the total rate of infection with parasites was $89.18 \%$ and this became more accurate and sensitive than microscopic examination, since the total infection rate in microscopy was $86.48 \%$ compared to the percentage of molecular examination, the infection rate in the group of people with cancer and diarrhea was $84.0 \%$ infected sample out of 50 samples Screened in the same group. The rate of infection is $100.0 \%$ of an infected sample out of 24 examined samples within the group of people with diarrhea only. The results of the statistical analysis showed a significant difference under the probability level $P=(0.048)$. The method of optical microscopy and molecular diagnostics, the PCR, has succeeded in identifying the vast majority of cases of parasite infestation, and the reason is due to the high rate of parasitic infection in cancer patients, especially colorectal cancer patients, as well as patients who transplant organs and primary immunodeficiency patients who are undergoing some treatments or drugs Chemical and radiological immunosuppression and their consideration as a risk group for microbial acquisition and parasitic infections ${ }^{(15)}$.In short, most of the intestinal parasitic infections such as Entamoeba histolytica and others are common in patients with primary immunodeficiency and in the group of cancer patients ${ }^{(16)}$.A study by ${ }^{(17)}$ stipulated an increase in the rate of infection when immunity decreased, explaining the causes and cases of decreased immunity, as it stated that the direct effect of radiation and chemotherapy leads to damage and destruction of blood-forming stem cells and that many chemotherapy agents used in Treating malignant diseases damages lymphocytes and thus suppresses cellular immunity, and that chemotherapy and X-ray therapy by killing cancer cells as a treatment through programmed cell death is generally considered an immunosuppressive, as well as radiotherapy affects many immune mechanisms in body tissues as well as a decrease in immune interleukins As well as the effect of direct radiation on tumors by modifying the phenotype of cancer cells to make them more likely to kill $\mathrm{T}$ cells, and therefore these radiation-induced changes in the tumor immune microenvironment promote greater infiltration into $\mathrm{T}$ cells (immune cells) and thus damage these cells, as mentioned previously, and immunotherapy must be combined with surgical intervention and chemotherapy ${ }^{(18)}$.Table 1-2 shows the molecular characterization of the cystine protease and $\mathrm{E}$. histolytica using the PCR method, and all investigated and PCR diagnosed cases showed positive results. As all results of gel electrophoresis were positive.

The results of completely positive infection of the examined samples are due to the fact that all the diagnosed parasites contain the virulence factors (cystine protease), which is known as a protein that the E. histolytica secretes for the purpose of survival within the host due to the immune defense lines that the host members use to resist the parasite invasion This protein is naturally produced by parasites during their invasion of the host due to the host's immunity and resistance to this invasion, as its presence indicates the presence of the parasite infection through the mechanisms that we will explain in detail below and in order for the protozoan parasites to cause an invasive intestinal infection, in order to lead to its pathogenicity and great mortality. The protective mucus layer must be disrupted by the secretion mechanism of the cysteine protein, as the cysteine proteins secreted from the amoeba parasite disrupt the protective mucous network of the gastrointestinal tract, thus overcoming the protective mucus barrier, as the mechanism of this protein breaks down the MUC2, which is the main structural component of the mucous chain Processes by targeting myosin and protein lysis, The main cleavage site degrades MUC2 polymers, thus inactivating the protective mucus gel. The ability of cysteine proteases to dissolve mucus gels can be seen by treating mucus from the MUC2-producing cell line with amoeba proteases, These results indicate a major role for cysteine proteases in overcoming the mucus protective barrier and the parasitic infection of 
invasive amebiasis occurs, the use of a specific cleavage mechanism used by an intestinal pathogen to disrupt the polymeric nature of mucin gel ${ }^{(19)}$. Intestinal pathogens must overcome a series of innate host defenses before contacting the intestinal epithelium. The first herpetic I encounter during an invasion is protection by the mucus barrier, mucus plays a protective role by being constantly renewed from epithelial cells and expelled in the intestine. The mucus traps both commensal and pathogenic microorganisms, and this mucus outflow ultimately removes these microorganisms during defecation, after successful colonization of the mucous layer From the digestive system by parasites the mucus barrier must be overcome, The present study also agrees with the study of ${ }^{(20)}$.

\section{Conclusion}

The current study concluded with determining the virulence factors of the amoeba histolytic parasite, as it was observed that all positive cases in the above parasite diagnosis contained a virulence factor and that all samples were positive for determining the virulence factor.

The partial examination was more accurate, sensitive and specific than the microscopic examination in diagnosing the above parasite

\section{Ethical Clearance: Nil}

\section{Source of Funding: Self}

\section{Conflict of Interest: Nil}

\section{References}

1. Verhagen, L. M., Incani, R. N., Franco, C. R., Ugarte, A., Cadenas, Y., Ruiz, C. I. S., \& Pinelli, E.” High malnutrition rate in Venezuelan Yanomami compared to Warao Amerindians and Creoles": significant associations with intestinal parasites and anemiaPLoS One, .(2013) 8(10).

2. Fox, S. I. "Human physiology".Stuart Ira Fox. 12th ed. p. cm. 9 Textbooks. I.(2011).

3. World Health Organization (WHO)." Communicable disease profile for Iraq". 19 March,(2003).

4. Lamm, M. E.. IV. "How epithelial transport of IgA antibodies relates to host defense". American Journal of Physiology-Gastrointestinal and Liver Physiology(1998), 274(4), G614-G617.
5. Tjota, M. Y., Hrusch, C. L., Blaine, K. M., Williams, J. W., Barrett, N. A., \& Sperling, A. I. "Signaling through FcR $\gamma$-associated receptors on dendritic cells drives IL-33-dependent TH2-type responses". Journal of allergy and clinical immunology(2014), 134(3), 706-713.

6. Campos-Rodríguezp, R., and Jarillo-Luna, A.” The pathogenicity ofEntamoeba histolytica is related to the capacity of evading innate immunity".Parasite Immunolgy.(2005), 27, 1-8. doi: 10.111 1/j.13 6 5- 3024.2005 .00743

7. Moonah, S. N., Jiang, N. M., and Petri, W. A. Jr." Host immuneresponse to intestinal amebiasis". PLoS Pathog. 9:e100348 9. doi:10.1371/journal. ppat. (2013), 1003489.

8. Kayser, Fritz H.; Bienz, Kurt A.; Eckert, Johannes and Zinkernagel, Rolf M. "Medical Microbiology". Georg Thieme Verlag, Rudigerstraße . Stuttgart, Germany. pp:)2005) 69814, 70469.

9. Haque, R.; Huston, C.; Hughes, M.; Houpt, E. and Petri W. Amoebiasis: "Review article". The New England. Journal of Medicine, (2003).348 : 1565 $-1573$

10. Calegar,D.A.;Nunes,B.C.;Monteiro,K.J..L.;Sant os,J.P.D.; Toma, H.K.; Gomes,T.F.;Lima,M.M.; Bóia,M.N.; \& Carvalho- Costa, F."AFrequency and molecular characterisation of Entamoeba histolytica, Entamoeba dispar, Entamoeba moshkovskii, and Entamoeba hartmanni in the context of water scarcity in northeastern Brazil". Memórias do Instituto Oswaldo Cruz, (2016), 111(2), 114-119

11. Lee, H. S., Jeon, S. W., Nomura, S., Seto, Y., Kwon, Y. H., Nam, S. Y., Ishibashi, Y., Ohtsu, H., Ohmoto, Y., \& Yang, H. M.)." Screening Biomarker as an Alternative to Endoscopy for the Detection of Early Gastric Cancer": The Combination of Serum Trefoil Factor Family 3 and Pepsinogen. Gastroenterology research and practice (2018), 2018, 1024074

12. Schiefer,W.C." stastistics for the biological science". 2nd ed. Addison. Wesley publcomp, California,London, (1980) .

13. McHardy, I. H., Wu, M., Shimizu-Cohen, R., Couturier, M. R., \& Humphries, R. M. "Detection of intestinal protozoa in the clinical laboratory". Journal of clinical microbiology .(2014), 52(3), $712-720$

14. Stark, D., Al-Qassab, S. E., Barratt, J. L. N., 
Stanley, K., Roberts, T., Marriott, D., \& Ellis, J. T.” Evaluation of multiplex tandem real-time PCR for detection of Cryptosporidium spp., Dientamoeba fragilis, Entamoeba histolytica, and Giardia intestinalis in clinical stool samples". Journal of clinical microbiology .(2011), 49(1), 257-262.

15. Esteghamati, A., Khanaliha, K., Bokharaei-Salim, F., Sayyahfar, S., \& Ghaderipour, M. "Prevalence of Intestinal Parasitic Infection in Cancer, Organ Transplant and Primary Immunodeficiency Patients in Tehran, Iran". Asian Pacific journal of cancer prevention .(2019), APJCP, 20(2), 495-501.

16. Aguilar, C., Malphettes, M., Donadieu, J., Chandesris, O., Coignard-Biehler, H., Catherinot, E., \& Suarez, F." Prevention of infections during primary immunodeficiency". Clinical infectious diseases .(2014), 59(10), 1462-1470

17. Kaur, P., \& Asea, A. "Radiation-induced effects and the immune system in cancer". Frontiers in oncology .(2012), 2, 191.

18. Bailey, C., Lopez, S., Camero, A., Taiquiri, C., Arhuay, Y., \& Moore, D. A. "Factors associated with parasitic infection amongst street children in orphanages across Lima, Peru". Pathogens and global health .(2013), 107(2), 52-57.

19. Shahi, P., Moreau, F., \& Chadee, K. "Entamoeba histolytica cyclooxygenase-like protein regulates cysteine protease expression and virulence". Frontiers in Cellular and Infection Microbiology .(2019), 8, 447.

20. Amat, C. B., Motta, J. P., Fekete, E., Moreau, F., Chadee, K., \& Buret, A. G. "Cysteine proteasedependent mucous disruptions and differential mucin gene expression in Giardia duodenalis infection". The American journal of pathology. (2017), 187(11), 2486-2498. 